\title{
A Study on Strategic Human Resource Management in Organizations at Oman
}

\author{
Dr.M.Nasrin Sulthana \\ Lecturer and CRE Coordinator, Gulf College, Mabaila, Oman

\section{Zuwaina Mohammed AL Amri, Zainab Lallbaksh Al Raisi, Amal Juma Alhasani, Laila Salim Al Farsi} \\ (Special Need) Students, Gulf College, Oman
}

\begin{abstract}
The topic Strategic Human Resource management will help the organizations in Oman to develop the competency skills of the personnel working in their organization. Sample sizes of 120 employees were chosen using simple random sampling technique. Descriptive analysis is followed us research design. Inductive approach as research approach is used which help the researcher to draft the theory on the analysis and survey as research strategy is used in this study. Primary data is obtained through questionnaire and secondary data through journals, books, internet and newspapers.
\end{abstract}

Keywords: Strategy, Human Resource, Management, Strategic plan, Competency Skills.

\section{INTRODUCTION}

It is a process that identifies current and future human resources needs for an organization to achieve its goals. Human resources planning should serve as a link between human resources management and the overall strategic plan of an organization. Aging worker populations in most western countries and growing demands for qualified workers in developing economies have underscored the importance of effective Human Resources Planning.

As defined by Bulla and Scott, human resource planning is 'the process for ensuring that the human resource requirements of an organization are identified and plans are made for satisfying those requirements'. Reilly defined workforce planning as: 'A process in which an organization attempts to estimate the demand for labour and evaluate the size, nature and sources of supply which will be required to meet the demand. Human resource planning includes creating an employer brand, retention strategy, absence management strategy, flexibility strategy, talent management strategy, recruitment and selection strategy.

\section{RESEARCH OBJECTIVE}

- To identify the effective planning strategies of human resources who involve in the development of skills

- To analyze the competencies in the long term as an input for optimal use of human resources in the system

- To evaluate the strategy related to human resources for the organizations in Oman.

\section{Literature REVIEW}

Our first task is to identify the principal dependent variables to be studied. Conceptualizing HR systems has been a major focus of the HRM literature over the past decade or more. The literature is extensive (Bamberger \& Meshoulam, 2001) and we touch here only on those aspects salient to the present study. Having identified relevant dimensions of an HR system, we will lay out our major hypotheses.

Business organizations currently working in an environment characterized by rapid change and complexity which led to increase the challenge in front of these organizations in their quest to create a competitive advantage. Organizations implement the internal strategy for management of external resources and environment at the same time (Lynch, 2001). 
Strategic planning is the essence of strategic management and process management tool that enables the organization to deal with future events efficiently and effectively and provide greater capacity to control its resources and also enable them to respond to environmental changes (Mondy, Noe, \& Mondy, 2005).

The planning One of the basic human resource management functions in the AST process human resources as it is a requirement A key to the rest of the other functions of human resources management Kalachtaar, recruitment and development, training, compensation and performance evaluation (homes \& Beach 2002).

\section{RESEARCH PHILOSOPHY}

Let's begin by considering what positivism is. In its broadest sense, positivism is a rejection of metaphysics (I leave it you to look up that term if you're not familiar with it). It is a position that holds that the goal of knowledge is simply to describe the phenomena that we experience. The purpose of science is simply to stick to what we can observe and measure. Knowledge of anything beyond that, a positivist would hold, is impossible. When I think of positivism (and the related philosophy of logical positivism) I think of the behaviorists in mid-20th Century psychology.

\section{INDUCTIVE APPROACH}

Inductive reasoning works the other way, moving from specific observations to broader generalizations and theories. Informally, we sometimes call this a "bottom up" approach (please note that it's "bottom up" and not "bottoms up" which is the kind of thing the bartender says to customers when he's trying to close for the night!). In inductive reasoning, we begin with specific observations and measures, begin to detect patterns and regularities, formulate some tentative hypotheses that we can explore, and finally end up developing some general conclusions or theories.

These two methods of reasoning have a very different "feel" to them when you're conducting research. Inductive reasoning, by its very nature, is more open-ended and exploratory, especially at the beginning. Deductive reasoning is narrower in nature and is concerned with testing or confirming hypotheses. Even though a particular study may look like it's purely deductive (e.g., an experiment designed to test the hypothesized effects of some treatment on some outcome), most social research involves both inductive and deductive reasoning processes at some time in the project. In fact, it doesn't take a rocket scientist to see that we could assemble the two graphs above into a single circular one that continually cycles from theories down to observations and back up again to theories. Even in the most constrained experiment, the researchers may observe patterns in the data that lead them to develop new theories.

\section{SURVEY}

Surveys can be divided into two broad categories: the questionnaire and the interview. Questionnaires are usually paper-and-pencil instruments that the respondent completes. Interviews are completed by the interviewer based on the respondent says. Sometimes, it's hard to tell the difference between a questionnaire and an interview. For instance, some people think that questionnaires always ask short closed-ended questions while interviews always ask broad open-ended ones. But you will see questionnaires with open-ended questions (although they do tend to be shorter than in interviews) and there will often be a series of closed-ended questions asked in an interview.

\section{ETHICAL IMPLICATION}

Ethical standards also require that researchers not put participants in a situation where they might be at risk of harm as a result of their participation. Harm can be defined as both physical and psychological. There are two standards that are applied in order to help protect the privacy of research participants. Almost all research guarantees the participants confidentiality -- they are assured that identifying information will not be made available to anyone who is not directly involved in the study.

\section{RESEARCH METHODOLOGY}

Data collection for this study was performed by using mailed questionnaire. The questionnaire consisted of two main parts. The first part consists of questions relating to HRM practices. The questions in this part is based on the list of HRM practice included in Schuler's HRM menu. Forty one items were developed to operationalize the practices listed in the menu. Respondents were asked to indicate whether they adopt these HRM practices. 
The second part sought information on the respondent firm's competitive strategy. This part is based on Dess and Davis's (1984) 21 item instrument. This instrument was developed by Dess and Davis to assess the competitive strategy of manufacturing firms. Since this study also included firms from the service sector, the instrument had to be adapted to include competitive methods which may be unique to the service sector. This was done by seeking the input of managers from the service sector. They were asked to describe the competitive methods used in their industry. The views of academicians specializing in this area and a review of relevant literature was also done to develop an understanding of the competitive issues in these service industries. After this review was done, 9 additional items were added to the instrument making it a 30 item instrument (refer to appendix 1).

Respondents were asked to describe the importance of these 30 competitive methods for their organizations. A 5 point Likert scale, with ' 1 ' indicating that a particular competitive method is not important at all and ' 5 ' indicating it is very important' was used to measure the importance of these competitive methods. Respondents were asked to choose ' 1 ' ' if a particular competitive method is not relevant to his/her organization.

The reliability of the 30 items strategy dimension was assessed. The analysis resulted in a coefficient Alpha $=0.888$.

\section{DESCRIPTIVE ANALYSIS}

Descriptive statistics are used to describe the basic features of the data in a study. They provide simple summaries about the sample and the measures. Together with simple graphics analysis, they form the basis of virtually every quantitative analysis of data.

Descriptive statistics are typically distinguished from inferential statistics. With descriptive statistics you are simply describing what is or what the data shows. With inferential statistics, you are trying to reach conclusions that extend beyond the immediate data alone. For instance, we use inferential statistics to try to infer from the sample data what the population might think. Or, we use inferential statistics to make judgments of the probability that an observed difference between groups is a dependable one or one that might have happened by chance in this study. Thus, we use inferential statistics to make inferences from our data to more general conditions; we use descriptive statistics simply to describe what's going on in our data.

Descriptive Statistics are used to present quantitative descriptions in a manageable form. In a research study we may have lots of measures. Or we may measure a large number of people on any measure. Descriptive statistics help us to simplify large amounts of data in a sensible way. Each descriptive statistic reduces lots of data into a simpler summary. For instance, consider a simple number used to summarize how well a batter is performing in baseball, the batting average. This single number is simply the number of hits divided by the number of times at bat (reported to three significant digits). A batter who is hitting .333 is getting a hit one time in every three at bats. One batting .250 is hitting one time in four. The single number describes a large number of discrete events. Or, consider the scourge of many students, the Grade Point Average (GPA). This single number describes the general performance of a student across a potentially wide range of course experiences.

\section{SAMPLING}

Sampling is the process of selecting units (e.g., people, organizations) from a population of interest so that by studying the sample we may fairly generalize our results back to the population from which they were chosen. Let's begin by covering some of the key terms in sampling like "population" and "sampling frame." Then, because some types of sampling rely upon quantitative models, we'll talk about some of the statistical terms used in sampling. Finally, we'll discuss the major distinction between probability and Nonprobability sampling methods and work through the major types in each.

\section{Simple RANDOM SAMPling TechniQues}

Once you've identified the theoretical and accessible populations, you have to do one more thing before you can actually draw a sample -- you have to get a list of the members of the accessible population. (Or, you have to spell out in detail how you will contact them to assure representativeness). The listing of the accessible population from which you'll draw your sample is called the sampling frame. If you were doing a phone survey and selecting names from the telephone book, the book would be your sampling frame. That wouldn't be a great way to sample because significant subportions of the population either don't have a phone or have moved in or out of the area since the last book was printed. 


\section{DATA ANALYSIS AND INTERPRETATION}

\section{Shrm Increases the Productivity}

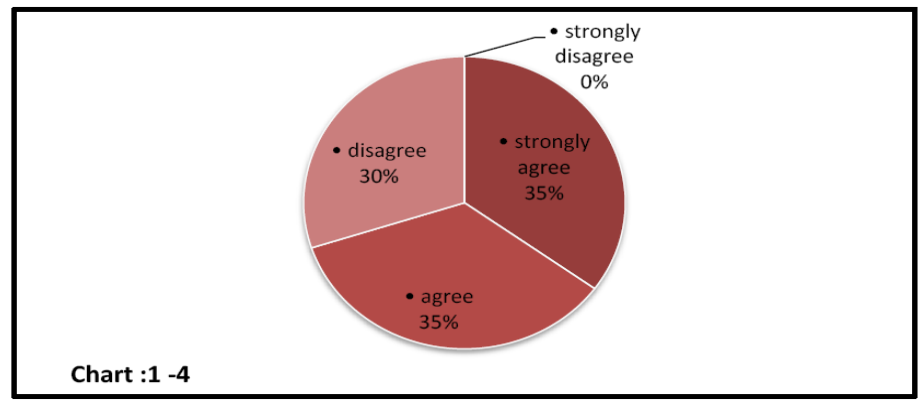

Above $35 \%$ of employees agreed and strongly agreed respectively that the SHRM increased the production of human resources and 30\% did not agree with the view. As they feel that the skills of the employees contribute more than the strategic plan.

\section{Shrm Give Importance to Employees}

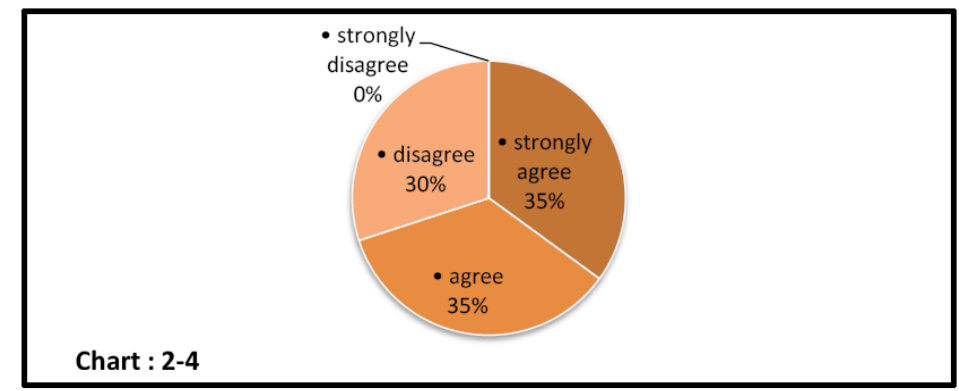

The second chart is $35 \%$ of the employment of persons who agree hard to raise the productivity of workers is also considered one of the important human resources and 30\% do not. Agee and hyped and $35 \%$. Employment: is to provide from within or outside the organization planned employment needs.

\section{Shrm Can Be Implemented by Qualified Staffs}

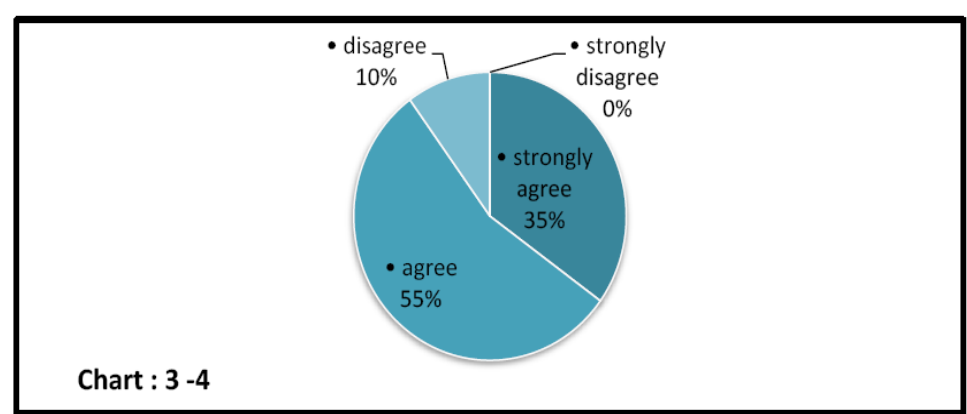

In the graph highest $55 \%$ of people who employee $35 \%$ agrees strongly reconcile, because it is the human resources is very important for employees $10 \%$ did not reconcile. Employee: is to maintain a qualified staff.

\section{Organizational Success}

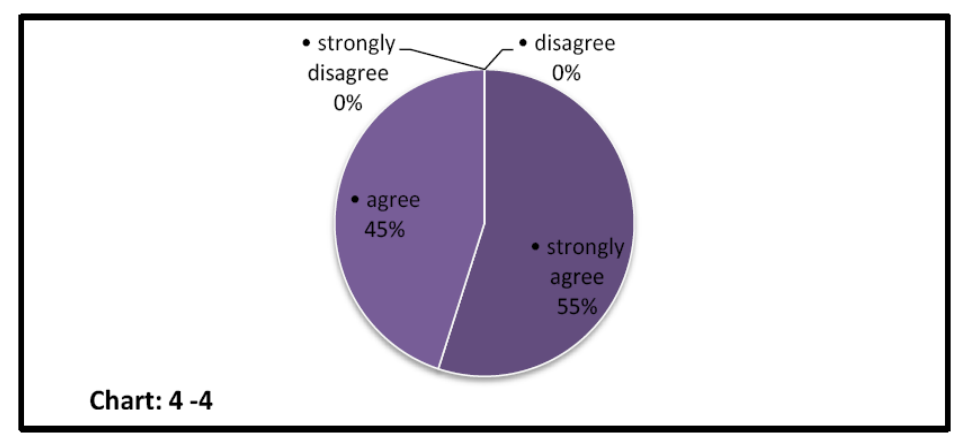


Graph the final $55 \%$ of people employee who strongly agree. $45 \%$ also agree that the workers of human resources in order to work too. The most important point for the ticket of toolkit this is the fundamental reason behind the effectiveness of human resources management: The main fact in all of these activities is to help your employees to succeed. If kept this goal at the forefront of your mind when applying these tools will be on the way to combine all the elements needed by your employees and your organization for success.

\section{FINDINGS AND SUGGESTIONS}

- From the above study it is clearly depicted that organization expect the workers to increase productivity more as $70 \%$ of the respondents say that the organizational goal is to increase productivity.

- $70 \%$ of the employees say that organization give importance to employees. It is true as they were provided on the job and off the job training to make their competencies skills strong so that they will not face any difficulty during the work.

- $90 \%$ of the respondents agreed that the employees recruited for implementing SHRM were qualified professionals.

- $100 \%$ of the employees feels that the organization will get success due to implementation of strategic Human Resource Management.

- The researcher suggested that the strategic plan should not be reinforced on the employees rather that slow revolutions make into big success. It is also suggested that the organizations should conduct survey periodically to get to know the need of their employees so that proper training will be provided to them to reach the success of the organizations.

\section{Conclusion}

The study addressed the issue of strategic planning of human resources, which is one of the core activities and practices performed by the human resources management in all types of institutions Through it estimated future needs of the organization from human resources to serve the requirements of achieving their goals and in order that the human resources planning the development of a future strategy based mainly on a study the volume of work specified in the organization's strategy and compare it with the power and the possibilities of future human resources in which to determine whether they need additional work force and what is unique and skills required to accomplish the work required in the future or that it has a surplus for the need of human resources, whether or not there is a shortage or surplus so that enough existing resources to accomplish what is planned from the workload of the overall strategy.

\section{REFERENCES}

[1] Anderson, (2013), IT and HRM, $6^{\text {th }}$ ed, New York, Prentice Hall.

[2] Azoulay, A. and J.-N. Kapferer. 2003. Do brand personality scales really measure Human Resources? J. Brand Management 11(2) 143-155.

[3] Bamberger. 2001. Reciprocal spillover effects: A strategic benefit of brand extensions. J. Marketing 67(January) 4-12.

[4] Barich, H. and P. Kotler. 1991. A framework for image management. Sloan Human Resource Management Rev. (winter) 94-104.

[5] Barth, M. E., M. Clement, G. Foster, R. Kasznik. 1998 Brand values and capital market valuation. Rev. Accounting Studies 3 41-68.

[6] Borden,(2013) Information Technology Impacts on Human Resource Management, $3^{\text {rd }}$ ed, Sage Publications

[7] Dess,(2012), Information Technology Impacts on Human Resource Management , $4^{\text {th }}$ ed, Harlow Press

[8] Bruner, (2011), Information Technology Impacts on in HR , $4^{\text {th }}$ ed , McGraw-Hill

[9] Euromonitor, Booz and company analysis...

[10] Iverson, (2012) Importance of Information Technology Impacts for Human Resource Management, $6^{\text {th }}$ ed, Thousand Oaks 
[11] Mondy, (2012), Importance of Information Technology in Managing HR Affairs , $4^{\text {th }}$ ed, New Age International.

\section{Questionnaire:}

\section{Project on Strategic Human Resource Management}

1. Human resource planning is one of the most important activities in modern organizations and management that the main role in the success of the organization and increase its effectiveness?

- strongly agree

- agree

- disagree

- strongly disagree

2. Known human resource planning as "the process by which the organization is seeking to obtain in a timely manner on the needs of capable and qualified to carry out the tasks entrusted to them to achieve the organization's goals workers"?

- strongly agree

- agree

- disagree

- strongly disagree

3. Show importance of the human resource planning in that it helps to dispose of surplus fill deficit, and thus in the rational use of human resources, a reduction in the labor cost to a minimum?

- strongly agree

- agree

- disagree

- strongly disagree

4. To ensure the success of human resources planning must provide reasons including: the accuracy of the organization's goals, and provide information and accurate data and support the senior management of the planning process and link human resources planning and other functions of human resources management?

- strongly agree

- agree

- disagree

- strongly disagree

5. The "government institutions" training and rehabilitation of competencies and human capacity, to cope with global technological developments in successive technical and cognitive areas.

- strongly agree

- agree

- disagree

- strongly disagree 